\title{
PROPAGANDA U ŠTAMPI „HRVATSKE KRAJINE” U VRIJEME BORAVKA VIKTORA GUTIĆA U BANJALUCI OD APRILA DO AVGUSTA 1941.
}

\begin{abstract}
APSTRAKT: Poslije stvaranja Nezavisne Države Hrvatske, Banjaluka je postala centar Velike župe Sana i Luka. Polovinom aprila 1941, u grad dolazi Viktor Gutić, Banjalučanin, koji, kao stožernik, utiče na ustašku propagandnu djelatnost. Vremenom, njegovo ime se sve više ističe u listu Hrvatska Krajina.
\end{abstract}

Ključne riječi: propaganda, Nezavisna Država Hrvatska, ustaše, Viktor Gutić, Banjaluka, Hrvatska Krajina, Ante Pavelić, muslimani

Poslije diobe Kraljevine Jugoslavije u aprilu 1941. između Njemačke, Italije, Mađarske i Bugarske, hrvatska buržoazija je ostvarila dugogodišnji san o osnivanju sopstvene države, zahvaljujući podršci Njemačke i Italije. Novostvorena država je nastala 10. aprila 1941. i bila je kvislinška tvorevina, u kojoj su na vlasti bili ekstremni velikohrvatski nacionalisti - ustaše. Država je dobila naziv Nezavisna Država Hrvatska, iako stvarno nije bila nezavisna već je djelovala kao protektorat Njemačke i Italije. U njenu teritoriju, koja je obuhvatala prostor od $110.000 \mathrm{~km}^{2}$, ulazile su Hrvatska, gotovo cijela Bosna i Hercegovina, Srem i Zemun, a istočna granica je bila na rijeci Drini. ${ }^{1}$ Centralni dio NDH činila je Velika župa Sana i Luka, čije središte je bila Banjaluka, a pored nje u ovu župu su bili uključeni i kotari Ključ, Sanski Most, Kotorišće (Kotor Varoš), Prijedor i kotarska ispostava Kozarac. ${ }^{2}$ U ustaškoj štampi ova teritorija je često nazivana Hrvatska Krajina - srce Nezavisne Države Hrvatske. Ustaški stožer za Bosansku Hrvatsku

${ }^{1}$ Izuzetak je činila Dalmacija, koja je Rimskim ugovorom pripala Italiji, a Međumurje Mađarskoj. Hrvatskoj je kasnije pripala teritorija od Splita do Dubrovnika sa ostrvima Hvar i Brač.

${ }^{2}$ Rajka Bućin, Prilog poznavanju institucija: zakonski okvir rada Velikih župa NDH, Arhivski vjesnik, Zagreb 2001, 209, 210, 221. 
i Povjereništvo za bivšu Vrbasku banovinu bili su osnovani 16. ili 17. aprila 1941. Ovaj datum veže se i za dolazak Viktora Gutića u Banjaluku. ${ }^{3}$ On je, kao ustaški stožernik u Banjaluci, $u$ to vrijeme počinjao rad na organizaciji ustaške vlasti. Njemu pripadaju i zasluge za osnivanje Ustaškog stožera za Bosansku Hrvatsku i Povjereništva za bivšu Vrbasku banovinu. Za taj dio $\mathrm{NDH}$, ustaška vlast je imala velike planove, koji su uključivali i premještanje sjedišta države $u$ Banjaluku, koja je trebalo da promijeni ime u Antingrad. ${ }^{4}$ Strahovlada Viktora Gutića u Banjaluci trajala je od polovine aprila do 21. avgusta 1941, kada je premješten u Zagreb. Prema izvještajima koje su u njemački informacioni ured slali povjerenici iz Zagreba, Viktor Gutić je sedmicama bjesnio u Banjaluci i u svojim govorima isticao da niti jedan Srbin neće živ napustiti taj grad. ${ }^{5}$

Ustaška organizacija je u takozvanoj Hrvatskoj krajini učvršćivala svoju vlast različitim zakonima. Ono što je obilježilo sam početak njihove vladavine bila je rasistička politika, koja je model imala u fašizmu i nacizmu. Sprovođena je ideja Mile Budaka koji je javno pozivao na istrijebljenje, pokatoličavanje i raseljavanje srpskog stanovništva. Ideologija ustaškog pokreta je bila nacionalistička, rasna, antisrpska i antisemitska. Državom je upravljao poglavnik Ante Pavelić. Ustaški stožernik u Banjaluci Viktor Gutić diskriminisao je Srbe i Jevreje mnogim novouspostavljenim zakonima i odredbama usmjerenim protiv njih. Jevreji su morali biti izuzeti iz sfere izgradnje i razvoja kulture u Nezavisnoj Državi Hrvatskoj, kao i Srbima, oduzimana im je imovina, morali su predati vlastima sve radio aparate, foto aparate, dvoglede, kamere i kino projektore. Diskriminacija je postojala i u javnom prevozu, kupanje na javnim mjestima i u banjama bilo im je zabranjeno, a morali su pristajati na prisilan rad bez novčane naknade. ${ }^{6}$ Svi ovi zakoni su bili objavljivani u javnom glasilu Hrvatska Krajina, stoga su korišćeni i kao sredstvo propagande protiv Jevreja i Srba, u cilju zastrašivanja. Za zamjenika Viktora Gutića bio je postavljen Feliks Neđelski, novinar i urednik Hrvatskog Glasa u Zagrebu. ${ }^{7}$ On je bio glavni propagandista u ovom dijelu NDH i ustašku ideologiju je širio među ustaškom omladinom.

Ustaše su još od uspostavljanja NDH veliku pažnju usmjerili na propagandne aktivnosti, dirigovane iz Hrvatske izvještajne službe pri Predsjed-

${ }^{3}$ Milan Vukmanović, Neka pitanja o obrazovanju i djelovanju Ustaškog stožera za takozvanu Bosansku Hrvatsku i Povjereništva za Vrbasku banovinu u Banjaluci od aprila do avgusta 1941. godine, Istorijski zbornik, br. 2, Banjaluka 1981, 155.

${ }^{4}$ Rafael Brčić, Kombinacije ustaša o Banjoj Luci kao „centru Nezavisne Države Hrvatske", Banjaluka u novijoj istoriji, Sarajevo 1976, 662.

${ }^{5}$ Bogdan Krizman, NDH između Hitlera i Mussolinija, Zagreb 1983, 134.

${ }^{6}$ Dušanka Kovačević i Zaga Umićević, Neki podaci o djelovanju Narodnooslobodilačkog pokreta u okupiranoj Banjaluci, Banjaluka u novijoj istoriji, Sarajevo 1976, 588.

${ }^{7}$ Hrvatska Krajina, br. 1, 20. travanj 1941, 2. 
ništvu vlade, odnosno kasnijeg Državnog izvještajnog i promidžbenog ureda pri Predsjedništvu vlade i Odjela za novinstvo Glavnoga ravnateljstva za promidžbu pri Ministarstvu prosvjete, sa nekoliko odsjeka. ${ }^{8} \mathrm{U}$ Banjaluci je djelovala ispostava DIPU-a, zadužena da prati i daje direktive $u$ vezi sa propagandom u Velikoj župi Sana i Luka. Ustaška ideologija bila je plasirana stanovništvu Hrvatske krajine putem plakata, letaka, velikih javnih skupova, priredaba i kulturnih večeri. Sve institucije kulture poprimile su duh ustaštva i bile su u službi širenja ustaške ideologije. No, najjednostavniji i najefektivniji način širenja ustaške riječi u propagandi bio je putem štampe. Tome je služila Hrvatska Krajina, glasilo ustaškog pokreta za teritoriju Hrvatske krajine.

Ustaška vlast je zabranila izlaženje svim predratnim listovima na teritoriji Velike župe Sana i Luka, izuzev Glasnika Banjalučke biskupije. List Hrvatska Krajina je izlazio u Banjaluci, a njegov prvi broj se pojavio samo četiri dana poslije uspostavljanja ustaške vlasti u gradu, 20. aprila 1941. Prvobitno je izlazio tri puta sedmično, utorkom, četvrtkom i subotom, a štampan je u štampariji „Braća Jakšić“ u Banjaluci. Tada je urednik lista bio Tomislav Cerovac. Uredništvo Hrvatske Krajine je u prvom broju napisalo da „potreba jednog dobro uređivanog hrvatskog lista u Banjoj Luci osjetila se već u prvim danima života Nezavisne Države Hrvatske. Bivši velikosrpski režimi nisu nikada dozvolili pokretanje jednog ovakvog lista. Podmuklom i sistematskom akcijom htjeli su oni uništiti hrvatski duh, hrvatsku svijest, kojim je prožeta Banjaluka i cijela Hrvatska krajina i nastojali su svim mogućim sredstvima pa tako i štampom širiti ideju velikosrpstva... Banjaluka kao prirodno i buduće političko središte Nezavisne Države Hrvatske ne smije ostati bez svojih novina, bez svoga glasila, koje će biti vjeran izražaj političkog, kulturnog i privrednog zbivanja ovih krajeva, njihove obnove i izgradnje." ${ }^{9}$

U prvom broju Hrvatske Krajine pisano je o postavljenju Viktora Gutića na mjesto ustaškog stožernika za područje bivše Vrbaske banovine i o Feliksu Neđelskom, postavljenom za njegovog zamjenika. List je o Gutiću pisao kao o nesebičnom nacionalnom i socijalnom radniku, koji je mnogo puta bio proganjan i zatvaran od bivših režima, a predstavljen je kao „nesavladivi hrvatski narodni borac obljubljen od ustaške i ostale hrvatske omladine u Banjaluci." ${ }^{10}$ Feliks Neđelski je bio priznati križarski radnik, a obavljao je dužnost predsjednika vrhovnog vođstva Križarske organizacije. Obojica su u banjalučkoj štampi predstavljani kao zaslužni Banjalučani, koji su se, poslije uspjeha u nacionalnom radu, vratili u svoj grad da pomognu učvršćivanje ustaške vlasti.

${ }^{8}$ HDA, Glavno ravnateljstvo za promidžbu pri Predsjedništvu vlade NDH, fond 237, Povijesni podaci o tvorcu fonda, 3.

${ }^{9}$ Hrvatska Krajina, br. 60, 13. rujan 1941, 1.

${ }^{10}$ Hrvatska Krajina, br. 1, 20. travanj 1941, 2. 
Propaganda u štampi Hrvatske krajine u vrijeme Viktora Gutića bila je usmjerena protiv srpskog dijela stanovništva, kome su se pripisivale zasluge za sve izmišljene i stvarne nevolje koje su snalazile stanovništvo $u$ nekadašnjoj Kraljevini Jugoslaviji. Nasuprot tome, muslimansko stanovništvo je bilo favorizovano. Prvi broj Hrvatske Krajine objavio je Proglas Hrvatskim Muslimanima, u kojem se ovaj dio stanovništva naziva najkorjenitijim i najplemenitijim dijelom junačkog hrvatskog naroda i poziva da preuzmu vlast, zadrže oružje i upotrijebe ga protiv Srba. U cilju pridobijanja muslimanskog stanovništva u Hrvatskoj krajini, u štampi su objavljivani propagandni tekstovi koji su upućivali na pokolje muslimana. Jedan takav tekst, objavljen u petom broju Hrvatske Krajine, nosi naslov Pokolj muslimana u Sandžaku. Tekstovi o srpskim zločinima nad muslimanima bili su česti, ali su ipak češći od njih bili oni koji su prikazivali „neizmjernu ljubav hrvatskog naroda prema Hrvatima muslimanske vjere". Prema pisanju Hrvatske Krajine, Viktor Gutić je u julu 1941. odobrio 300.000 dinara za gradnju društvenog Muslimanskog kulturnog doma u Banjaluci. Ova vijest izazvala je oduševljenje banjalučkih muslimana. ${ }^{11}$ Nasuprot tome, pokolji nad srpskim i jevrejskim narodom bili su zataškivani, a u štampi je čak i zaprijećeno da će pred Prijekim sudom završiti svi koji budu širili lažne glasine o progonima i zločinima izvršenim nad Srbima i Jevrejima, kao i oni koji bi ugrozili život ili imovinu bilo kojem stanovniku NDH. ${ }^{12}$

List Hrvatska Krajina je donosio ekskluzivne intervjue sa Viktorom Gutićem i drugim značajnim ličnostima, u cilju veličanja ustaškog pokreta i poglavnika. Audijencije kod poglavnika uvijek su zauzimale naslovne strane i o njima je opširno pisano. U jednom takvom intervjuu, koji je Gutić dao po povratku iz službene posjete Zagrebu, o Anti Paveliću on kaže sljedeće: „Svi mi bili smo oduševljeni nastupom dra Pavelića i njegovim junačkim držanjem. Svež u zdravlju, ozbiljna lica, otvorena pogleda, dr. Ante Pavelić daje sliku velikog umnika, genija, vođe čestitog naroda kao što je naš Hrvatski, vojskovođe koji je nakon povratka iz 12-godišnjeg dragovoljnog sužanjstva garancija za očuvanje granica, Nezavisnosti, Slobode i budućnosti Hrvatske Države. Prije odlaska iz sobe još nam je jednom Poglavnik stisnuo ruku i doviknuo: Pozdravite nam Bosnu!"'13. Ovaj dio teksta upućuje na zaključak da je Viktor Gutić u svojim intervjuima agitovao za Antu Pavelića i da je plasirao informaciju kako poglavnik voli Bosnu jer se i sam osjeća Bosancem. Ovakvi tekstovi su služili pridobijanju muslimanskog dijela stanovništva Bosne i Hercegovine. Ante Pavelić je slavljen u svakom tekstu i svim izjavama koje su davali ustaški zvaničnici. Mile Budak je za Hrvatsku Krajinu izjavio: „Spasila nas je

\footnotetext{
${ }^{11}$ Hrvatska Krajina, 13. srpanj 1941, br. 37, 1.

${ }^{12}$ Hrvatska Krajina, 29. lipanj 1941, br. 31, 1.

${ }^{13}$ Hrvatska Krajina, 24. travanj 1941, br. 3, 1.
} 
bezprimjerna vjera u pravednost naših zahtjeva i Poglavnikovo genijalno vodstvo... Vjera je stvorila našu Nezavisnu Državu Hrvatsku, vjera će je i učvrstiti i urediti pod vodstvom našeg dragog Poglavnika." ${ }^{4}$ Lik i djelo Ante Pavelića predstavljani su u nekoliko prvih brojeva lista, a njegove zasluge za stvaranje Nezavisne Države Hrvatske su isticane sve vrijeme tokom izlaženja lista. Ovo njegovanje kulta poglavnika predstavlja kopiranje nacističke i fašističke propagande, u kojoj je Vođa zauzimao najznačajnije mjesto. Pored idealizovanja njegove ličnosti, u štampi Hrvatske krajine je pisano o velikim proslavama poglavnikovog imendana i rođendana. Sve ove proslave imale su propagandni karakter. Rođendan Ante Pavelića je svečano proslavljen 13. juna 1941, tako što su organizovane mise, svečanosti za građane na Petrićevcu i svečani ručak za hrvatske i njemačke vojnike u hotelu Bosna. Štampa je pisala i o detaljima sa proslave, gdje se ističe govor Viktora Gutića, u kojem je on veličao djela poglavnika i Ante Starčevića. ${ }^{15}$

Propagandu prilagođenu potrebama hrvatskog i muslimanskog stanovništva u Bosni i Hercegovini, koja je trebalo da služi njihovom pridobijanju, potvrđivala je ideja o prebacivanju centra NDH u Hrvatsku krajinu, plasirana u štampi i putem propagandnih govora. U vrijeme boravka Viktora Gutića na mjestu ustaškog stožernika u Banjaluci, postojala je intenzivna propaganda o Banjaluci kao novom centru Nezavisne Države Hrvatske. Šesti broj Hrvatske Krajine, koji je izašao 1. maja 1941, na naslovnoj strani je objavio tekst Hrvatska državna vlada dolazi u Banjaluku. Sam tekst objašnjava da je zagrebačka radio stanica javila kako će se vlada preseliti u Banjaluku, a da će kao njeni prvi predstavnici doći odjeljenja veterinarstva, rudarstva i šumarstva, zatim i potpredsjednik vlade Osman Kulenović, pa postepeno i cijela vlada. Za Banjaluku su bili vezani mnogi planovi, pa je tako grad trebalo da promijeni ime $\mathrm{u}$ Antingrad, da bi se na taj način odalo priznanje Anti Starčeviću i Anti Paveliću. ${ }^{16}$ Ideja je napuštena poslije glasnog neodobravanja banjalučkih muslimana. Propagiranje hrvatstva je ipak nastavljeno putem promjene naziva ulica, bulevara i trgova u Banjaluci, tako da su ulice nosile imena Ante Pavelića, Ante Starčevića, Matije Gupca, Slavka Kvaternika i drugih „hrvatskih velikana“.

Štampa je isticala putovanja Viktora Gutića po Hrvatskoj krajini i njegove susrete sa narodom, posjete samostanima i crkvama, od kojih je najviše pisano o posjetama franjevačkom samostanu na Petrićevcu u Banjaluci. Naslovnice lista donosile su naslove poput „Stožernik dr. Viktor Gutić dobio je naročite pohvale sa Najvišeg mjesta za svoj dosadašnji rad“ ili „Velika

\footnotetext{
${ }^{14}$ Hrvatska Krajina, 24. travanj 1941, br. 3, 2.

${ }^{15}$ Hrvatska Krajina, 15. lipanj 1941, br. 25, 2.

${ }^{16}$ R. Brčić, $n$. d.
} 
briga Stožernika dr. Viktora Gutića za zdravstvene potrebe žitelja Bosanske Hrvatske ${ }^{17}{ }^{17}$

Iako se ime Ante Pavelića najčešće pojavljivalo na naslovnicama Hrvatske Krajine, Viktor Gutić je prijetio da zasjeni njegovo ime. Samouvjereni banjalučki stožernik pojavljivao se u gotovo svim brojevima lista sa novim hvalospjevima, njegovo ime je bilo nezaobilazno na proslavama, držanju govora, po njemu su nazivane ulice, stadioni, institucije. Mjesec dana se gotovo svakodnevno pisalo o njegovom odlasku na novo namještenje u Zagreb. Ti tekstovi su govorili o spontanim manifestacijama ljubavi iskazanim pri ispraćaju Gutića, pa na kraju i o njegovom boravku u Zagrebu. Objavljen je i Proglas Gradskog Poglavarstva, povodom odlaska Gutića iz Banjaluke, u kojem, između ostalog, stoji: „Njegov odlazak je težak gubitak za naš grad i cijelu ovu Hrvatsku krajinu, jer pokraj njegovih neprocjenjivih zasluga za očuvanje naše slobode, naših života $i$ imetka našeg, bila bi potrebna i daljnja njegova prisutnost u našoj sredini za dobro naše. Iako odlazi iz naše sredine, on nas neće zaboraviti, nego će i dalje posvećivati svu pažnju svoje plemenite hrvatske duše svome rodnome gradu i njegovoj okolici." 18

Stožernik se opraštao sa stanovništvom lično, u svim kotarima Hrvatske krajine, a o tome je list opširno pisao. O samom odlasku na novu službu u Zagreb, Gutić je za list Hrvatska Krajina izjavio: „Sretan sam što ću moći u Zagrebu po direktivama Poglavnika nastaviti rad za dobro drage nam domovine Hrvatske. Dakako da će mi i na novoj dužnosti u Zagrebu ležati na srcu napredak i moje drage Hrvatske Krajine i Banje Luke. ${ }^{19} \mathrm{O}$ svom odlasku je još rekao: „Stavljam se na raspolaganje Poglavniku Dr. Anti Paveliću da Mu služim čitavim svojim srcem i svom ljubavlju kao ocu i spasitelju Domovine." ${ }^{20}$ Povodom odlaska Viktora Gutića iz Banjaluke, Gradsko poglavarstvo je u javnom glasilu Hrvatska Krajina objavilo proglas u kojem su se pozivali svi građani da se 10. avgusta 1941. okupe ispred hotela Bosna, kako bi se na taj način pokazala odanost i zahvalnost Gutiću za sva njegova „velika djela“ koja je učinio. Ime Viktora Gutića u listu Hrvatska Krajina prestaje da se javlja polovinom avgusta 1941, nekoliko dana poslije njegovog odlaska sa dužnosti stožernika u Banjaluci, iako time ne prestaje njegov uticaj na genocidnu politiku prema nehrvatskom stanovništvu Bosanske krajine.

Mada je na suđenju za ratne zločine održanom 1947. izjavio da nije imao nikakve veze sa kontrolom štampe u Bosanskoj krajini, pa čak da je nije niti čitao, ${ }^{21}$ mnoge propagandne ideje su nestale poslije odlaska Gutića

${ }^{17}$ Hrvatska Krajina, 28. svibanj 1941. godine, br. 18, 1, Hrvatska Krajina, 1. lipanj 1941, br. 20, 1.

\footnotetext{
${ }^{18}$ Hrvatska Krajina, 10. kolovoz 1941, br. 49, 1.

${ }^{19}$ Hrvatska Krajina, 8. kolovoz 1941, br. 48, 1.

${ }^{20}$ Isto.

${ }^{21}$ Glas, Organ Narodnog fronta za okrug Banjaluku, 8. februar 1947, br. 6, 4.
} 
sa dužnosti iz Banjaluke, a jedna od najznačajnijih - premještanje centra Nezavisne Države Hrvatske u Banjaluku - potpuno gubi na značaju i ne pominje se u sredstvima informisanja i propagande. Ustašku propagandu u Banjaluci u vrijeme boravka Viktora Gutića karakterišu demagogija, laž, rasizam, propagiranje nasilja i mržnje, širenje lažnih vijesti i kopiranje fašističkih i nacističkih ideja. 
Marijana Todorović Bilić

\section{THE PROPAGANDA IN THE BANJA LUKA PRESS DURING THE EARLIEST PERIOD OF THE INDEPENDENT STATE OF CROATIA 1941}

\section{Summary}

The article reviles the press in the Banja Luka during the early days of Independent State of Croatia, especially during the presence of the Viktor Gutic, who was the leader of the local Ustasa authorities. In the period between the April and August 1941, there were only two newspapers: one of the local catholic bishopry, and another one, called the Croatian Krajina, which was analyzed by the article. This newspaper was created after the creation of the new Croatian state, and acted as the propaganda tool of the local Ustasa authorities. It promoted Ustasa movement ideology, by the standpoints it acted as weapon against proclaimed enemies. The other aim was to attract the Muslim population to support the new state and authorities. One of the special themes was the idea of the transfer of Croatian Government from Zagreb to Banja Luka. This idea was strongly advocated by the Viktor Gutic himself, and when he later left the Banja Luka, it was completely abandoned. The author concluded the Croatian press in the Banja Luka used the language of violence, primarily against the Serbs. 